INTERNATIONAL JOURNAL OF

MULTIDISCIPLINARY STUDIES IN ART AND

TECHNOLOGY

\title{
An analytical study on a selection of the artist Esmat Dawestashy's artworks during Coronavirus (Covid-19) Pandemic in Egypt
}

Dr. Marwa Wadie Fathy Abdallah*

Smouha, Alexandria, 21500, Egypt.

\begin{abstract}
Artists were not immune to the perils that beset humanity, as pandemics afflicted artists everywhere, including the Coronavirus (Covid-19) pandemic that afflicted the entire world. Egyptian painters like Esmat Dawestashy established a precedent for the relationship between art and the environment. Hence, the analysis of several of Esmat Dawestashy's artworks revealed that he was influenced by a cultural heritage that enriched his artwork with different painting styles.

The research question is: what are the symbols and motifs that Esmat Dawestashy used in paintings to represent the Coronavirus pandemic? Esmat Dawestashy's artwork was examined for the most important artistic features. The researcher used Howard Risatti's criticism theory, which consists of three basic stages: descriptive analysis, form analysis, and meaning analysis, to analyze a selection of the artist's works on the Coronavirus Pandemic in order to identify the elements and motifs that inspired the artist Esmat Dawestashy to express the Coronavirus Pandemic through painting. Since the outbreak of the Coronavirus pandemic in 2020, a selection of Esmat Dawestashy's works has been studied. The selected artworks discussed how the pandemic is depicted, as well as the events that influenced the artwork, such as the quarantine, communication, and the artist's optimism about the end of this calamity. The researcher presented the study findings; especially, the creative qualities of artist Esmat Dawestashy's work during Coronavirus pandemic which led to the research results.
\end{abstract}

\section{Keywords}

- Artist Esmat Dawestashy

- An analysis

- Art of painting

- Coronavirus pandemic

\section{Introduction}

The world is currently in a state of panic as a result of the outbreak of this novel pandemic (Covid-19) all over the world. Consequently, man managed to realize his abilities against this disease. In fact, this condition that mankind is experiencing was not the first of its kind, but man has been through this conflict before, when the plague swept through the countries of Europe during the medieval period in addition to other pandemics against which man was

\footnotetext{
* PHD in Art history and appreciation, Faculty of Specific education, Art education Department, Alexandria University, 2020.
} 
helpless. Art played a prominent role in expressing civilization in that period, which indicates that in every distress there is hope and from the womb of crises, creativity is born with a unique artistic character to form a part of human history and society.

Art cannot cure diseases, especially Coronavirus that swept the world. However, it is meant to record the events and disasters that afflict humanity. Art is not only concerned with documenting history, ideas and philosophy of the artist, the beliefs and development of society, but also understanding reality, expressing developments around the world, and giving hope to the recipient. At this stage, artists can express this phenomenon through his feelings, and make art a historical witness to dealing with these events, each with its own style and thought.

In the medieval period, and even after the Renaissance, medical conditions were not perfect. There are many artworks depicting doctors while facing the disease in a costume consisting of a coat, a mask with a bird-like beak filled by a pleasant-smelling materials, gloves and shoes. This mask had glass openings for the eyes as it was designed to eliminate foul odors, which are thought to be the primary cause of plague. In addition, the doctor is wearing a wide-brimmed leather hat to refer to their profession. They used wooden sticks to point to areas that needed care and examined patients without touching them. With these simple possibilities, the artist portrayed the heroic role the doctor plays ${ }^{(1)}$.

In fact, there are several artists who managed to use their artwork to express pandemics. For example, the artist (Arnold Böcklin) ${ }^{(*)}$ portrayed the plague in a symbolic way in the form of a huge monster sweeping the city and killing all the people. This monster is in human shape, the head of a skull, a black body, a tail and wings resembling a dragon.

Moreover, the artist (Egon Schiele) ${ }^{(* *)}$ made a piece of art entitled (The Family). The painting depicts a time when Europe was ravaged by the Spanish flu, which caused the death of millions of people across the continent ${ }^{(2)}$.

In the present time, the world is suffering from Coronavirus pandemic, which had an impact on Egypt as a whole; specifically plastic art. As Egyptian art has interacted with this danger, artists began expressing this pandemic, each in their own style. Some artists portrayed humanity as suffering from this pandemic. One of the most prominent artists who expressed this pandemic

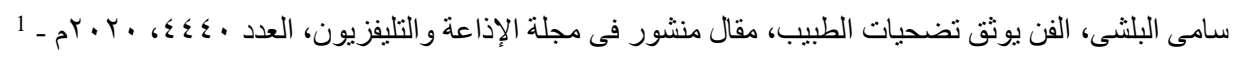
https://www.facebook.com/samy.elbalshy.5

* - Arnold Böcklin (1827-1901), Swiss symbolic painter.

** - Egon Schiele (1890 - 1918) was an Austrian painter and visual artist. He is considered one of the leading artists of the twentieth century. His paintings depended on the expressive style.

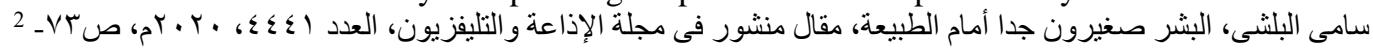
https://www.facebook.com/samy.elbalshy.5
} 
is Esmat Dawestashy. He started expressing this period from January, 2020 AD to the present time, and called it "Every Day Painting". Every artistic group bears an artistic character and a name resulting from what the artist felt when facing this pandemic. The researcher aimed to present an analytical study on selections of Esmat Dawestashy's artwork during the Coronavirus pandemic in Egypt, where a huge amount of artwork are documenting such important period in our lives. The researcher uses the critical theory of Howard Risatti in analyzing artworks to reveal internal and external meanings in these artworks.

\section{Research problem background}

There is a kind of interaction between the individual, the prevailing events in the world, and following the developments of the Coronavirus pandemic and looking forward to its end. Thus, artists were also affected by these events. Looking at a selection of the works of artists who expressed this type of human tragedies from pandemics, we will learn how the artist deals with the idea of the pandemic, symbols and motifs in artworks which enrich the field of plastic art. By investigating artworks that express the Coronavirus pandemic as wearing a mask and gloves the researcher realized that this pandemic cannot be expressed in the artistic methods and the cultural heritage by which the artist was affected. Esmat Dawestashy is one of the most talented painters who used this artistic style to represent the Coronavirus pandemic.

\section{Research problem}

The research problem lies in revealing the plastic elements used by Esmat Dawestashy to represent the Coronavirus pandemic through the analytical study of the critical theory of Howard Risatti. Hence the research question came as follows:

What are the plastic symbols and elements Esmat Dawestashy used to represent the Coronavirus pandemic in Egypt through painting?

\section{Research objectives}

The research aims to identify the plastic symbols and elements that inspired the artist Esmat Dawestashy to express the Coronavirus pandemic in Egypt in the field of painting.

\section{Research importance}

The research importance is reflected in the artistic documentation of a pivotal period in human life and the struggle against Coronavirus pandemic in Egypt through the paintings of the artist, Esmat Dawestashy.

\section{Research hypothesis}

To answer the research question, the research hypothesis was formulated to focus on the impact of Coronavirus pandemic on the work of the artist, Esmat Dawestashy, in the field of painting. 


\section{Research limits}

A. Artistic limits

The research sheds light on a selection of artwork by the Egyptian artist, Esmat Dawestashy, which express the Coronavirus pandemic in Egypt in the field of painting. These artworks are (the devil is coming, the Sad Angels Await, intimate relationships in the time of Corona, the black pandemic hits the beauties, goodbye, the devil departs before Ramadan).

B. Spatial limits

It deals with the artworks in Egypt by the Egyptian arist, Esmat Dawestashy.

C. Time limits

The researcher analyzes a selection of Esmat Dawestashy's artwork in 2020.

D. Objective limits

The researcher uses Howard Risatti's critical theory in analyzing artworks.

\section{Research Methodology}

The researcher followed the analytical description method to a selection of Esmat Dawestashy's artwork that depicts Coronavirus crisis.

\subsection{Artist Esmat Dawestashy (1943)}

The artist Esmat Dawestashy graduated from the Faculty of Fine Arts in 1967, and is considered to have a distinct creative experience. These creations are linked to the folk and legendary origins in Egyptian heritage. His works are distinguished by bright, very strong colors. There are other artworks in black and white. He sometimes adds decorations or symbolic signs to those artworks because its elements are popular, live, and metaphysical, such as ritual magic works. Therefore, these colors and elements harmonize in tight kinetic formative relationships while retaining their innateness and expressiveness ${ }^{(1)}$.

\subsection{The artistic features of Esmat Dawestashy's artworks (until the pre-Corona period)}

Dawestashy's art is distinguished by essential features that have affected him throughout his artistic career and until the present time, such as the construction of the work and the dialogic language loaded with details of place and time. The place refers to where the artist lives which influenced his features and his journey in life. The time is represented by the artist's inspirations from traditional arts, especially folk arts and decorations. Therefore, most of the plastic motifs

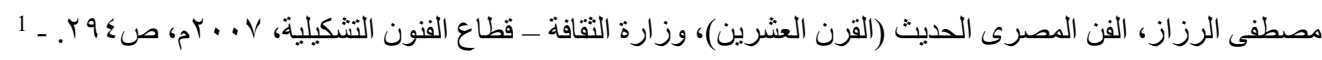


used by the artist are not only symbols of metaphysical meanings, but also elements of a reality that is observed and expressed in a simple instinctive sense $\mathrm{e}^{(1)}$.

He was also inspired by the idea of frame in folk arts. He divided the artwork into four parts to achieve symmetry in the plastic elements, with the addition of the decorative element to achieve a plastic rhythm through repetition and symmetry. In addition, the spaces are not left without decorations with the diversity of its units besides the harmony of chromaticity and streamlines $^{(2)}$.

Therefore, the artworks of Esmat Dawestashy are distinguished by an epic character because they reflect events as if the artist establishes a visual dialogue with them. They are filled with rich touches and details, fine lines and vivid colors. The vividness in the artist's expressive style indicates the artist's personality that transcends usual feature through the use of human elements, plastic elements, decorations, fine lines and colors. The human elements transcended the usual between elongation, exaggeration, deletion, addition, simplification, and summarization, as well as giving dynamic expressive features through line and color mixed with the artist's emotions. Human elements were not only subjected to these plastic treatments, but the artist also used other plastic elements with humans such as the angel, the devil, the bird besides other elements and features with ancient Egyptian, Coptic, Arab, Islamic roots and African masks. Therefore, there are many features with historical dimensions and cultural legacies. He is inspired by heritage and ancient civilizations to simulate artistic formations that serve Egyptian life with its inherited manifestations and contemporary movement ${ }^{(3)}$. He emphasizes the latent meanings and ideas of those elements to convince the recipient that the rituals and symbols carry meanings in an artistic formulation influenced by human reality, where the artist unleashes his imagination to express his feelings ${ }^{(4)}$.

The artist is also characterized by an innate style and abstraction in expression. He defines the elements in an explicit line which is reflected in the precise and clear composition of the elements. He resorts to flattening and avoids the perspective side, which contributes to the similarity of expression on the artwork. In addition, he used the diagnostic elements that

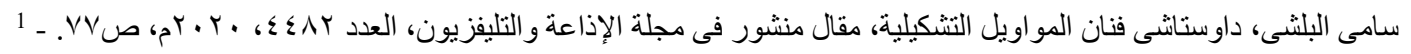
https://www.facebook.com/samy.elbalshy.5 
characterize the artist and his decoration. He also used geometric shapes; the crescent, the star and the palm, and hot and strong colors ${ }^{(1)}$.

With the use of those plastic elements, which is expressed by the softness of his lines, he adds to them some traditional decorations mixed with his decorations, which he created and established to overlap with one another in a homogeneous fabric ${ }^{(2)}$.

Therefore, Esmat Dawestashy's paintings are distinguished by two factors. The first factor is the plastic elements and symbols or folk motifs derived from historical beliefs and dimensions. The second factor is the aesthetic perception represented in the diversity of formulation of these elements. Due to the diversity of cultural and social changes, perceptions of these symbols and folk elements vary and their plastic formulations change to keep abreast with the development of civilizations ${ }^{(3)}$.

\subsection{An analytical study on a selection of Esmat Dawestashy's artworks during the Coronavirus outbreak in Egypt}

Since the outbreak of the Coronavirus pandemic in 2020, a selection of Esmat Dawestashy's artworks has been studied analytically. The selected artworks revealed how the pandemic is depicted, as well as the circumstances that influenced the artwork, such as the quarantine, people communication, and the artist's optimism about the end of this calamity. To conduct an analytical study on these artworks, the researcher uses "Howard Risatti's"(*) critical theory, which is a gradual critical approach for describing and analyzing all elements of the artwork. The researcher's goal is to study the aspects and elements employed in building the artwork.

This critical theory relies on three basic stages (descriptive analysis, formal analysis, and meaning analysis, which is divided into internal analysis and external analysis or internal meanings, and external meanings).

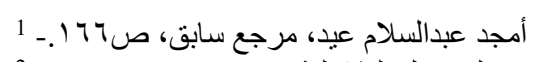

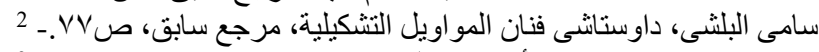

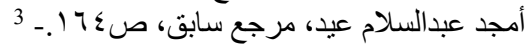

* - Howard Risatti is a critic specialized in art criticism and art history in the twentieth century. In 1987, he developed a systematic critical method for describing and analyzing works of art. This critical theory explains صافية عبيد المطيرى، مدى تطبيق معلمات التربية الفنية لمبادئ النقد الفنى التعليمى بالمرحلة المتوسطة فى . criticism in DBAE theory.

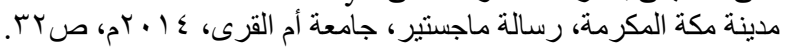


First: Descriptive Analysis ${ }^{(1)}$

It is the first level in Risatti's artistic criticism and a crucial stage in understanding the artwork. Knowing, describing, and realizing the motifs and elements that make up the artwork, including the subject of the artwork, the visual elements that can be seen in the artwork, and the components of the artwork; their relationship to the subject of work and their relationship to each other, is essential to the analysis. It is concerned with the description of the artwork's subject, or the issue it addresses. As a result, the critic and art connoisseur must be able to recognize and define the elements that comprise the artwork. This step is more applicable to diagnostic projects.

\section{Second: Formal Analysis}

It is the ability to analyze an artwork in terms of its form and to uncover visual links between shapes, lines, and colors. The significance of formal analysis is determined by how well abstract or non-objective art is comprehended. The artist's use of organic or geometric forms, cold and warm colors, and diverse types of lines, as well as the relationship between them are essential. The importance of the formal elements appears in the way they interact with each other to create aesthetic and artistic values ${ }^{(2)}$.

Third: Meaning Analysis ${ }^{(3)}$

Meaning analysis comprises of two parts:

\section{1- Internal Analysis (internal meanings)}

As part of its subject, it is concerned with addressing the aspects and values of the artwork's internal elements. These meanings include the symbolic or narrative elements of the painting, which are linked to descriptive and formal analysis ${ }^{(4)}$, as well as the nature of the painting, its symbols, and the meaning inferred from its internal structure ${ }^{(5)}$.

\section{2- External Analysis (external meanings)}

External meanings are aspects that aid in the comprehension of an artwork. They are found outside of it, including various contexts such as the artistic background. It is important to understand the artwork school; whether it's an abstract, expressive, or cubism approach, as well as the political or ideological context, which focuses on the relationship between artwork

\footnotetext{
1 - Risatti, H., Art Criticism in Discipline - Based Art Education, Source: The Journal of Aesthetic Education, University of Illinois press, Vol. 21, No. 2, p.221.

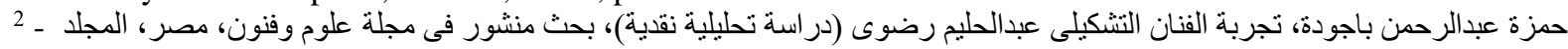

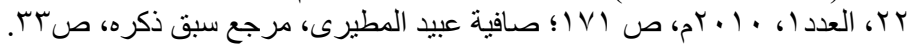

3 - Risatti, H., (Vol. 21, No. 2), op.cit. p.222.

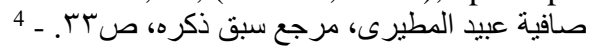

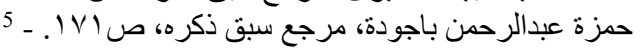


and political beliefs, such as capitalism or socialism. Nonetheless, psychology focuses on the relationship between artwork and Freud's school of psychoanalysis. Consequentially, the general vision of the artwork contributes greatly to the richness and depth of the process of criticism $^{(1)}$.

Through the previous three main stages in this critical method, the researcher designed a table to analyze the selected artworks in light of Howard Risatti's theory. This is as follows:

\section{First: Descriptive analysis}

It addresses: A- Artwork components

B- Artwork description

C- Elements relationship to the artwork subject

\section{Second: Formal analysis}

It addresses: A- Elements in the artwork, which are:

\begin{tabular}{|c|c|c|}
\hline 1-line & 3-texture & 5-color \\
\hline 2-form & 4-dark and light & 6-space \\
\hline
\end{tabular}

B- Structural system in the artwork, which is:

1-Artwork axes

2-Focus point

3- Compatibility and contrast

4- Deletion, additions and modification

C- Aesthetic foundations in the artwork:
1-unity
3- Balance
5- proportionality
4- Dominance

5- Overlay and overlap

6- Depth and flatness

7- Transparency

\section{D- Formal relations in artistic work:}

1-The relationship between the lines in the artwork.

2- The relationship between the sizes in the artwork.

3- The relationship between the colors in the artwork.

4- The relationship between the textures in the artwork.

\section{Third: Meaning analysis}

It includes: A- Internal meanings

B- External meanings

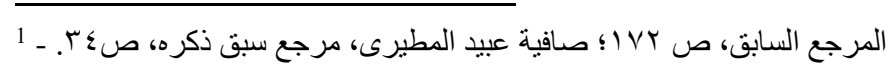


The selected artworks of the artist Esmat Dawestashy, which expressed the Coronavirus pandemic, include six artworks which are: (The devil is coming, the Sad Angels Await, intimate relationships in the time of Corona, the black pandemic hits the beauties, goodbye, the devil departs before Ramadan). These artworks are from Esmat Dawestashy's official page ${ }^{(1)}$.

\section{1- The Devil Is Coming}

The artist, Esmat Dawestashy, depicted, in a symbolic manner, the beginning of the Coronavirus pandemic in its devilish form.

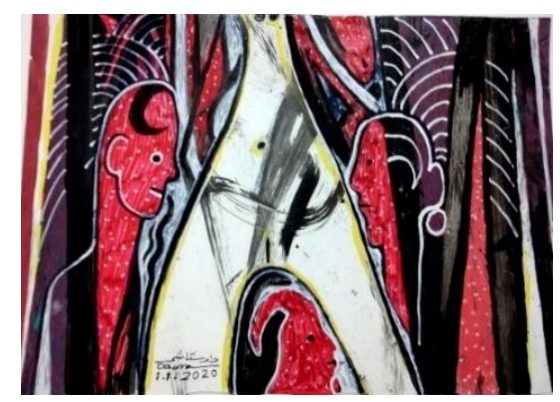

Figure 1: Esmat Dawestashy (The Devil is Coming) - different colors on paper - 25 x 35 cm - 2020.

First: Descriptive analysis of the artwork (The Devil Is Coming)

A- Artwork components: human elements, lines and dotted motifs are used in the painting.

B- Artwork description: The artist depicted four human elements. On both sides of the painting, there is a woman and a man with devil horns and in the middle of them is another human element at the forefront of the painting surrounded by a black palm, which contributed to the symmetry of the work. In addition, there was another face in background on the right side of the painting, and the middle is occupied by a ghost-like shape, from which only the eyes, represented by the two black dots, are visible.

C- Element relationship to the artwork subject: coronavirus is likened to the horned devil, the coming white ghost, and the depiction of these human elements in red and black.

\section{Second: Formal analysis of the artwork (The Devil Is Coming)}

\section{A- Artwork elements:}

1- Lines: white lines in the human element are used to show them clearly. Arched lines are also used on both sides of the artwork, which highlighted the symmetry in addition to the use of black longitudinal lines.

\footnotetext{
1 - https://www.facebook.com/esmat.dawestashy
} 
2- Form: the artwork is characterized by its flatness, containing the organic forms of simplified human elements.

3- Texture: it appeared clearly in the human figures, which the artist gave the dotted feature to distinguish it from the painting's background.

4- Dark and light: the artwork was dominated by simplification and symbolism, so the artist dispensed with light and shade.

5- Color: the red, yellow, black, and white colors are used. It turns out that these colors are associated with the idea of the artwork, where the artist showed the devil in red black lines resembling bars interspersed with a violet color space on both sides, and the mysterious body that looks like a ghost in white.

6- Space: the spaces were occupied by human elements, a ghost-like body which was filled with colors, dotted decorations, curved lines and longitudinal lines.

7- Movement: the repeated arched lines created a sense of movement in the artwork.

\section{B- Structural system in the artwork:}

1- Artwork axes: the artwork relied on the oblique and curved vertical axes. It is through the curved line in the middle of the painting that the hierarchical formation of the figure of the coming ghost is made and among the vertical diagonal lines, the devils appear.

2- Focus point: it is on the left side of the artwork, which is represented by the red devil and its black horns.

3- Compatibility and contrast: the color and linear contrast was evident in the artwork, as the artist moved quickly between black, red and white, as well as the thick and thin lines, which confirmed the meaning of the artwork.

4- Deletion, addition and modification: the highly abstract diagnostic elements appeared, and the artist reduced many details in the physical features and body. It is characterized by extreme elongation, and the addition of the horns as a symbolic meaning to embody the concept of the devil.

5- Overlay and overlap: there is a partial overlap in the artwork, which is emphasized by the linear overlap and chromatic intersections adding richness to the composition.

6- Depth and flatness: the artwork is characterized by flatness and simplicity in the artist's symbolic expression of the advent of Coronavirus represented by devils. 
7- Transparency: the colors were characterized by strength and clear linear intersections, especially the outer lines of the human elements.

\section{C- Aesthetic foundations in the artwork:}

1- Unity: it is achieved through the overlapping elements in the artwork, the unity of style, color techniques and their meaning.

2- Rhythm: it was achieved through the linear repetition of the arc lines on the right side and the same on the left side with a slight difference in its formation, thus achieving a non-monotonous rhythm in the artwork.

3- Balance: Asymmetric balance is achieved through the linear arc rhythm on both sides of the artwork as well as the red color throughout the artwork.

4- Dominance: the color of the artwork is predominantly red and black. The chromatic dominance was achieved through the white space in the middle of the artwork to highlight the upcoming vague ghost.

5- Proportionality: it is achieved through the white form and the two devil elements on both sides of the artwork. Besides, there is also proportionality between the black and red colors.

Through the artwork formal analysis, it becomes clear that there are significant relationships between colors, sizes, lines and textures in the artwork.

\section{D- Formal relations in the artwork:}

1- The relationship between the lines in the artwork: linear intersection resulted in a sense of unity of composition, and the lines varied between vertical diagonal lines, arc lines, heavy and fine lines. The use of lines in defining the elements gave the artwork a linear richness and tightness.

2- The relationship between the sizes in the artwork: the sizes of the three devils are quite similar to each other. They appeared on both sides of the artwork and in the middle in the foreground, while the size of the fourth devil's face in the background lines was smaller.

3- The relationship between the colors in the artwork: there is harmony between the red and black colors, which were interspersed with dark violet and white to highlight the artwork meaning. 
4- The relationship between the textures in the artwork: The textures varied between chromatic, linear and dotted spaces. The dotting method dominated the red-colored spaces, which represented by the devils.

\section{Third: Meaning analysis of the artwork (The Devil is coming)}

A- Internal meanings: As the artist, Esmat Dawestashy, expressed the Coronavirus pandemic in its early stages with the devil and his image in the form of a man and a woman with horns and red bodies, which is the symbolic feature of the devil's appearance, and in order to be associated with the Coronavirus pandemic, the artwork suggests anticipation. These dots were applied to the bodies to represent the coronavirus pandemic, which had circular bumps. The artwork's background was pervaded with red with white dots to symbolize the devil as sneaking between the black longitudinal lines. The artist depicted the ghost figure in the center of the artwork to express his concern.

B- External meanings: Although the artist expresses the novel coronavirus pandemic and the new events in the world, it is clear the he is influenced by the cultural heritage through the symbolic colors that express the devil and its symbolic features.

\section{2-Sad Angels Await}

Esmat Dawestashy expressed in an abstract way the fear and sadness that engulfed not only the world and man, but also the angels.

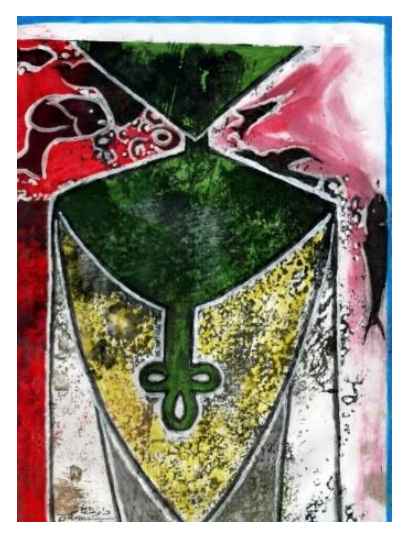

Figure 2: Esmat Dawestashy (Sad Angels Await) - different colors on paper - 25 x 35 cm -2020.

First: Descriptive Analysis of the artwork (Sad Angels Await)

A- Artwork components: abstract geometric shapes and organic motifs.

B-Artwork description: The angel is portrayed in the form of a human body from highly abstract geometric structures, where the face is depicted in a green triangular shape with black brush strokes interspersed with it, so the features were completely hidden. He wears 
a mantle resembling a cleric with an ornament that resembles the key of life (ankh sign), but in an inverted position in green color with black brush touches, and the rest of this mantle is shown between yellow and white with the addition of black effects. In the background, there are abstract organic units of fish and birds as if they were swimming in space.

C- Element relationship to the artwork subject: the embodiment of the sad angel in a silent, still form, and wearing clothes that resemble a cleric.

\section{Second: Formal analysis of the artwork (Sad Angels Await)}

\section{A- Artwork elements:}

1- Line: straight diagonal lines are used to depict the face, and diagonal, curved and vertical lines in depicting the body. The two adjacent lines method was also used to determine the main angelic element between black and white.

2- Form: geometric formations that are highly abstract and flat.

3- Texture: black brush touches to the color areas are used to give a sense of roughness which is evident in the shape of an angel.

4- Dark and light: The dark side is represented on the left side of the background of the artwork, where the intensity of the red color becomes clear, which ranges from the light red color to white on the right side of the painting.

5- Color: the harmony of the hot color, which is the red color in its degrees in the background of the artwork, with the colors of the main element, which is the angel consisting of green, white, yellow, and black interspersed them to give the artwork a state of sadness.

6- Space: the space is represented in the background of the artwork that the artist filled with color spaces of red tones in addition to the abstract organic elements.

7- Movement: Through the embodiment of the angel from the front end, the stability of the physical condition, and the hands gave the artwork a state of stillness, which emphasized the depth of the idea of the artwork.

\section{B- Structural system in the artwork:}

1- Artwork axes: it consists of vertical and oblique axes which added stillness to the artwork.

2- Focus point: it is the green space that covered the face and the front area of the angel's clothes. 
3- Compatibility and contrast: contrast is achieved between the size of the main element represented by the angles which took a large space, and the small organic elements in the background of the artwork, which confirmed the value of the artwork.

4- Deletion, addition and modification: modification is used in the physical body, which was clearly manifested in the formation of the face into a triangle, as the artist resorted to simplification and deletion of details.

5- Overlays and overlaps: There are color overlays through bright color areas with black brush touches, which enriched the color values in the artwork.

6- Depth and flatness: the artwork is characterized by its extreme flatness and simplification.

7- Transparency: strong colors free of color transparency are used.

\section{C- Aesthetic foundations in the artwork:}

1- Unity: it was formed through the unity of the idea, and the abstraction of the elements from details.

2- Rhythm: The rhythm is not monotonous as the main element in the artwork is in a fixed form with color gradations in the background, and some details, which resulted in rhythmic harmony in the aesthetic elements and colors.

3- Balance: the achievement of the axial balance helped to highlight the basic plastic element in the artwork which covered a large space giving a sense of symmetry.

4- Dominance: it is manifested in the green color from the group of cold colors that emerged amid the group of hot colors. The dominance of the element in the form of the abstract element of the angel, which occupied a large space, highlighted the depth of meaning.

5- Proportionality: There is proportionality between the size of the main element that is manifested in the angel, and the elements that are scattered in the background of the artwork to stress the meaning and to show the angelic form.

Through the artwork formal analysis, it becomes clear that there are significant relationships between colors, sizes, lines and textures in the artwork. 


\section{D- Formal relations in the artwork}

1- The relationship between the lines in the artwork: the size of the lines was unified in black and white.

2- The relationship between the sizes in the artwork: the sizes varied remarkably between the two sizes of the main element (the angel), and the scattered elements in the background of the artwork.

3- The relationship between the colors in the artwork: The uses of hot colors and cold colors varied, which gave color richness to the artwork.

4- The relationship between the textures in the artwork: The rough texture is unified in the main element (the angel), which helped to confirm it.

\section{Third: Meaning analysis of the artwork (Sad Angels Await)}

A- Internal meanings: The artwork carries the meanings of sadness. The artist, Esmat Dawestashy, discovered the fierce pandemic that threatens humanity, which caused panic, fear and sadness all around. The state of sadness is not only felt by human beings, but the artist portrayed a sad angel in an expressive human form, free of details, and still, as if in a state of anticipation.

B- External meanings: It seems that this artwork is linked to the artist's fear of this pandemic that might affect the dearest people. It is worth noting that the artist's artistic style appeared clearly in his depiction of the human body through summarization and simplification.

\section{3-Intimate Relationships in the time of Corona}

The artist, Esmat Dawestashy, expressed in a symbolic and expressive way the method of communication between people in the time of Corona.

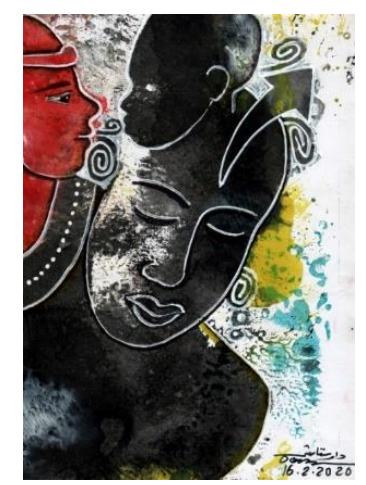

Figure 3: Esmat Dawestashy (Intimate Relationships in the time of Corona) - different colors on cardboard $20 \times 30 \mathrm{~cm}-2020$. 
First: Descriptive analysis of the artwork (Intimate Relationships in the time of Corona)

A- Artwork components: human elements, curvilinear and free motifs are used in the artwork.

B- Artwork description: He depicted three faces inspired by African art, where the thick lips, and the skull, which is dominated by magnification, were painted in successive sizes. A face appeared with a part of the upper body of a large size, as if it appears at an inclined angle from the left side in black, so that another head in black is depicted on the side, to meet on the left side of the artwork the head of another person in red. The artist surrounded these elements with some spiral lines coming from the mouth and head and an arrow. The left side of the artwork is occupied by a white space interspersed with light blue and yellow spots.

C- Element relationship to the artwork subject: the artist's depiction of arrows and spiral lines as a means of communication between people. Depicting people in black and red color reflects the Coronavirus pandemic. The white space, which represents the artwork background, is saturated with spots of color as if it is a space that receives signals to resend them.

\section{Second: Formal analysis of the artwork (Intimate Relations in the time of Corona)}

\section{A- Artwork elements:}

1- Lines: the line is used to emphasize and define the artwork elements, where he used the black and white lines successively to identify the elements, in addition to the use of curved, spiral and oblique lines. This linear diversity added richness and visual diversity to the artwork.

2- Form: human elements are used with simplification and abstraction, in addition to free and highly simplified linear decorations.

3- Texture: they are unified in the artwork elements and the background as well, as a result of the color staining method in the artwork.

4- Dark and light: it is clearly manifested in the human element at the forefront of the artwork, through the intensity of black on the right side of the face, to show a white light on the left side of this face.

5- Color: the artist followed the method of color staining, which was clearly evident in the background of the artwork. There is a chromatic harmony that helped to emphasize the human elements through black, which was evident in the white 
background with color spots of cold and hot colors in light blue and yellow. In addition, the use of the red hot color helps to show the elements.

6- Space: it emphasizes the elements represented by the group of people in successive kinetic rhythms that gave vitality to the artwork.

7- Movement: The diversity in the directions of people and their gradation gave a sense of motion through time and place along with a repetitive kinetic rhythm.

\section{B- Structural system in the artwork}

1- Artwork axes: it consists of oblique axes and curves.

2- Focus point: it is represented in the person in the middle of the artwork, whom the artist surrounded with a group of spiral lines and arrows to appear as a source of transmission to make the recipient's eye go all around the artwork.

3- Compatibility and contrast: the color contrast between the black represented in the diagnostic elements and the white represented in the background of the artwork became clear, which confirmed the meaning of the artwork.

4- Deletion, addition and modification: the diagnostic elements are characterized by simplification and reduction to show the most prominent expressive features of the artistic heritage.

5- Overlays and overlaps: the overlay and partial overlap is achieved between the diagnostic elements, which gave the artwork a unity of composition.

6- Depth and flatness: it is characterized by its flatness, which gives the artwork an expressive simplicity.

7- Transparency: there is no transparency as the artist relied on the color intensity and its strength, using the color staining method.

\section{C- Aesthetic foundations in the artwork:}

1- Unity: the coherence and interdependence of the diagnostic elements achieves unity in the artwork. In addition, the formulation of the diagnostic elements and their gradual divergence emphasizes the unity of meaning in regard to the relationships between people during the Coronavirus pandemic.

2- Rhythm: The free rhythm is achieved through the repetition of the diagnostic elements and their different sizes with different spacing between them, so the kinetic rhythm of these three elements is created. 
3- Balance: balance is illusory in the artwork, through the plastic construction of the artwork elements and the multiplicity of diagnostic elements, which gave a sense of vision permanency.

4- Dominance: the dominance of the diagnostic element size that occupied the front of the artwork sends messages to the outside world without direct communication with people. The color dominance is also achieved in showing the person in red as if he is receiving the message.

5- Proportionality: There is proportionality between the sizes of the three diagnostic elements, which suggested continuity, and between the colors of the elements and the background, especially black and white, which added to the color balance and the balance between mass and space.

Through the formal analysis of the artwork, it becomes clear that there are significant relationships between colors, sizes, lines and textures in the artwork.

\section{D- Formal relations in the artwork}

1- The relationship between the lines in the artwork: there is a connection between the lines of the artwork elements, in addition to the diversity of linear formations between arched lines, oblique lines, and spiral lines, achieving harmony and linear richness.

2- The relationship between the sizes in the artwork: the sizes of the diagnostic elements varied, the largest is the human element that occupied the front to the artwork, then the person who appears in red, followed by the person who is reduced to the human head and who appears from the head of the human who occupied the front of the artwork.

3- The relationship between the colors in the artwork: there is a chromatic harmony between the hot colors, especially red, and the neutral colors manifested in black.

4- The relationship between the textures in the artwork: The textures of the artwork are unified in the idea of color staining with the tactile and color effects it causes.

\section{Third: Meaning analysis of the artwork (Intimate Relationships in the Time of Corona)}

A- Internal meanings: The artwork suggests isolation. The artist expressed the idea of communication and the relationship between individuals in the time of Corona through the means of communication, as he showed it through the arrows and spiral lines that 
appear in front of the mouth, contrary to the previous communication through visiting and greeting. The colors are limited in particular the diagnostic elements are in black and red, which are colors that express that atmosphere of anticipation, fear and caution.

B- External meanings: the artwork expresses a difficult period, a period of lockdown, non-visiting, caution and fear. The painting expresses that period, in which the artist uses his own artistic features and cultural heritage. It is clear that he is influenced by African art as he highlighted the most important features in the African face.

\section{4- The Black Pandemic Hits The Beauties:}

The artist, Esmat Dawestashy, used an expressive style in a portrait of women during the peak of the Coronavirus pandemic, which affected the entire world.

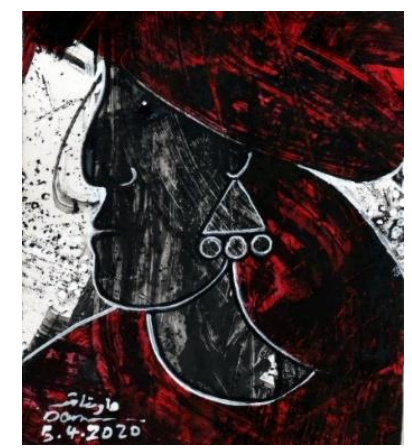

Figure 4: Esmat Dawestashy (The Black Pandemic Hits the Beauties) - black, red and white ink on paper $-20 \times 25 \mathrm{~cm}-2020$.

\section{First: Descriptive analysis of the artwork (The Black Pandemic Hits the Beauties):}

A- Artwork components: the human element is used in the artwork.

B- Artwork description: a human-woman element is portrayed from the side, looking in the left direction of the artwork. She is portrayed in black skin, with withered eyes, her body in the form of a black dot with another white dot on it. The artist added to that body some ornaments, a circular earring on the nose inspired by folk art. She wears a red hat; her short red hair appears from under the hat. She wears a red robe. The artist depicted this body on a white background with black ink stains.

C- Element relationship to the artwork subject: the artwork colors are limited to red and black to cope with the atmosphere. The eyes appear to be dominated by fading and fatigue. 


\section{Second: Formal analysis of the artwork (The Black Pandemic Hits the Beauties):}

\section{A- Artwork elements:}

1- Line: the black line followed by the white line is used to define the artwork elements which distinguished the artwork. In addition, the artist used curved and geometric lines.

2- Form: a female figure is used in an elegant artistic composition.

3- Texture: The personal element was dominated by the rough texture resulting from the longitudinal, transverse and oblique brush movement from black to red and white. In the background, there are effects of black bubbles, which added diversity in texture and technical richness of colors.

4- Dark and light: it relied on the intensity of explicit chromaticity with the addition of extended brush touches in black to the element.

5- Color: they are limited to the neutral colors of black and white, and the hot color represented by the red color, which the artist also worked on with black, to stress meaning of caution.

6- Space: the space around which the effect of the scattered inks as bubbles emphasizes the composition of the artwork.

7- Movement: There is stillness and solidity in the element of women, which is manifested in the stability of movement and the look of still narrow eyes to express the extent of fatigue and fear.

\section{B- Structural system in the artwork}

1- Artwork axes: they consist of the curves that are manifested in the external linear formation of the woman, and in the formulation of the details of the element. This resulted in the interaction between these lines and the recipient with the details of the artwork.

2- Focus point: it is manifested in the color where the black color focus is represented in the skin of the woman in the middle of the artwork, so that the recipient interacts with the details of the face.

3- Compatibility and Contrast: there is a linear discrepancy between the use of arched lines in the woman's plastic formulation, which is prevalent in the artwork, and the geometric linear formation of the earring that the woman wears, which resulted in the linear diversity of the formulation. 
4- Deletion, addition and modification: the artwork is characterized by the amplification of the element of the woman's face, the extreme reduction of the eye, and the summarization of details, as it appears inconsistent with the standards of beauty for women, so that the artist emphasizes the impact of the Coronavirus pandemic on humans and women.

5- Overlays and overlaps: there is a chromatic overlay in using the red color and then adding black hatching lines, as well as by adding the white hatching lines on top of the black.

6- Depth and flatness: the artwork is characterized by the flatness of the artwork elements, and the depth of the artwork's meaning.

7- Transparency: it relied on the strength of color and its clarity with the diversity of color methods.

\section{C- Aesthetic foundations in the artwork:}

1- Unity: it is represented by the interconnection of the lines of the artwork in a harmonious linear formation. In addition, the unity of colors is consistent with the meaning of the artwork.

2- Rhythm: There is a free rhythm through the diversity of spaces for both sides of the woman element, which gives the artwork diversity and reduces the sense of monotony.

3- Balance: it is achieved between the mass of the element, represented in the woman, and the space in the background, which enriches the plastic form of the woman.

4- Dominance: there is linear and color dominance, as the linear dominance is represented in the geometric lines of the earring that the woman wears in the middle of the arched lines, and the color dominance manifested in the hot color (red) with the neutral colors of (white and black), which achieved the color and linear richness.

5- Proportionality: There is proportionality between the mass of the element represented in the woman and the space, as the woman occupied a large space to emphasize the meaning of the artwork.

Through the artwork formal analysis, it becomes clear that there are significant relationships between colors, sizes, lines and textures in the artwork. 


\section{D- Formal relations in the artwork:}

1- The relationship between the lines in the artwork: there is a correlation between the lines of the artwork that helped in the unity of the composition. There is diversity between the curved and geometric lines that emphasized the diversity in the linear richness.

2- The relationship between the sizes in the artwork: the woman size topped the artwork space. There is difference in the jewelry size between the earring and the nose.

3- The relationship between the colors in the artwork: there is a chromatic harmony between the neutral colors (white and black), and the hot colors represented by the red color.

4- The relationship between the textures in the artwork: through the diversity of chromatic styles between the element and the background, the diversity between the textures is achieved.

\section{Third: Meaning analysis of the artwork (the black pandemic hits the beauties)}

A- Internal meanings: The artwork bears the meanings of fatigue, as the artist explained the effect of corona on an element characterized by an aesthetic character. This is embodied in the woman, as he depicted her with withered eyes, and emphasized that the coarse color texture of the element to show the extent of the ferocity of this pandemic, the woman wears a hat, and ear and nose jewelry. It is clear that the artist symbolizes the difference of cultures and that the pandemic is all over the world with different nationalities, cultures and customs.

B- External meaning: The artist, Esmat Dawestashy, followed his distinctive artistic style, in which he used amplification and modification in the plastic formulation of the human element in his artworks.

\section{Goodbye}

The artist, Esmat Dawestashy, expressed his optimism about the end of the Coronavirus pandemic crisis. 


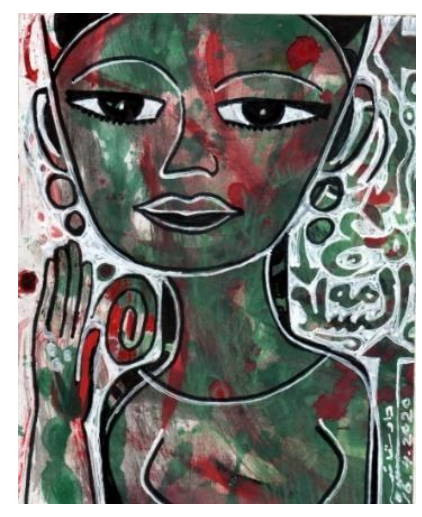

Figure 5: Esmat Dawestashy (Goodbye) - colors on paper - 20 x $25 \mathrm{~cm}-2020$.

\section{First: Descriptive analysis of the artwork (goodbye)}

A- Artwork components: a human element, a woman, curved and circular motifs, arrows, and a phrase in Arabic (goodbye) are used.

B- Artwork description: the artist portrayed a woman who occupies the artwork space, predominantly green with scattered colors of red, and with features influenced by ancient Egyptian art. He portrayed her as she raised her left hand bidding farewell, and surrounded by a spiral circle and other circles of various sizes. The right side of the artwork background is occupied by curvilinear motifs and arrows, with the word "goodbye" written.

C- Element relationship to the artwork subject: the green color as a symbol of goodness and peace and the expressive movement of the hands to say goodbye are used to indicate that the artist is optimistic about the near end of the Coronavirus pandemic crisis.

\section{Second: Formal analysis of the Artwork (goodbye):}

\section{A- Artwork elements:}

1- Lines: curved, circular, and spiral lines, in addition to the longitudinal lines formed in the arrows are used with black lines followed by white to define the elements of the painting, which gave the artwork a decorative character.

2- Form: there is richness in the diversity of the artwork elements. This is evident in the artist's use of the human element represented by the woman, and the decorations represented by curved and spiral lines, arrows and Arabic writing.

3- Texture: The effect and texture of the brush appear in the longitudinal direction of the green color with a scattering of red spots to show the uniformity of texture in the artwork.

4- Dark and light: The artist dispensed with the principle of dark and light in the artwork. 
5- Color: the color economy is reflected in the artwork, as the artist combined the hot colors represented by the red color, and the cold colors represented by the green color, on a white background.

6- Space: the artist exploits the space to give a decorative character around the main element in the artwork, making the recipient's eye wander around the artwork.

7- Movement: through the curved lines of the woman element and the arched decorative lines and the scattering of the red color in an irregular way, a sense of linear movement is reflected.

\section{B- Structural system in the artwork:}

1- Artwork axes: they consisted of curves in the formation of women, which give the artwork the flow and tightness of composition.

2- Focus point: it lies in the size, which is represented in the expressive portrait of the woman who covered a large space in the artwork.

3- Compatibility and contrast: There is a chromatic contrast. The dominant color is green, then the red color scattered in different parts, achieving visual diffusion.

4- Deletion, addition and modification: the artwork was distinguished by deleting details, and modifying the proportionality of the diagnostic body, especially between the small size of the hand and the physical structure of the woman.

5- Overlays and overlaps: there is a chromatic overlay as the main color of the elements (women, pottery, and Arabic writing) is green, and the scattered color of red is superimposed over it.

6- Depth and flatness: the artwork is characterized by the flatness and simplification of the artwork elements.

7- Transparency: There are color reflections as a result of red scattering over green.

\section{C- Aesthetic foundations in artwork:}

1- Unity: Placing the word "Goodbye", the waving hand, the harmony of colors, and the coherence of the elements contributed to achieving unity in the artwork.

2- Rhythm: The non-monotonous rhythm is achieved through the of the woman's portrait in the middle of the artwork, on the right side of the painting is occupied by arched decorations and arrows, and writing (goodbye), while on the left side of the painting her hand is waving bidding farewell to the coronavirus pandemic and some circular and spiral decorations. 
3- Balance: it is pivotal, there seems to be symmetry of both sides of the artwork, but there is difference in the decorative details of both sides of the background of the artwork, the richness of the design elements and the decorative character is achieved.

4- Dominance: the dominance of size, especially the woman's face, to show in the woman's eyes a look of optimism for a breakthrough to get rid of the pandemic.

5- Proportionality: There is proportionality between the artwork elements and the invisible meaning of the content of the artwork as the artist hopes for an end of the pandemic.

Through the formal analysis of the artwork, it becomes clear that there are significant relationships between colors, sizes, lines and textures in the artwork.

\section{D- Formal relations in the artwork}

1- The relationship between the lines in the artwork: the fine lines of black and white are used in defining the artwork elements in addition to the broad color lines used in the decorative formations and Arabic writing.

2- The relationship between the sizes in the artwork: The size of the woman covers a large area of the artwork. As for the rest of the elements, which are represented in the decorative formations, the woman's hand and the Arabic writing are noticeably reduced and are of nearly the same size.

3- The relationship between the colors in the artwork: There is a chromatic harmony between the group of colors that are limited to green and red, in addition to the neutral colors that the artist always used in black and white.

4- The relationship between the textures in the artwork: The textures of all the artwork elements which depend on the color spaces are unified, so that some of the white paper space appears through them.

\section{Third: Meaning analysis of the artwork (goodbye)}

A- Internal meanings: There are internal meanings that the artwork carries, including the title of the artwork (goodbye), and optimism. The artist emphasized this meaning by the writing which became one of the artwork elements. He feels certain that this ordeal will come to an end. On the opposite side of the phrase, appeared the woman's hand with her palm raised to emphasize the meaning of the end of the pandemic. He represented the coronavirus by the spiral shape that adjoins the palm in an indication of the end of 
that crisis, in addition to the appearance of the clear and wide eyes which shine with hope, a decent smile, peace and calm on the face.

B- The external meanings: The features of the woman are clearly influenced by the cultural heritage of the artist, as it appears like one of the faces that were engraved on the walls of the temples. This is emphasized by the green color, the scattered red color, in addition to the Arabic writing in a decorative composition that enriched the artwork. It is worth noting that this artwork illustrates the artist's challenge to this pandemic through this artwork, which he implemented during the peak of the pandemic.

\section{6-The Devil Departs Before Ramadan}

The artist, Esmat Dawestashy, expressed in a symbolic way his optimism for the end of the Coronavirus pandemic.

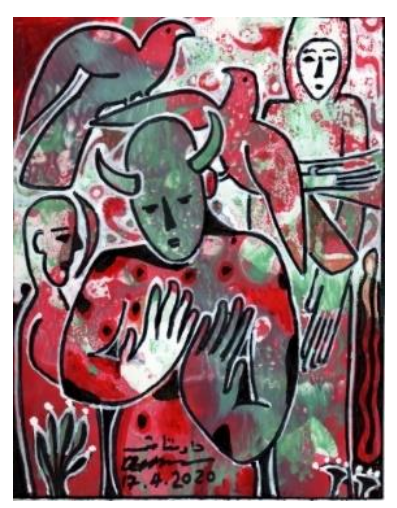

Figure 6: Esmat Dawestashy (The Devil Departs before Ramadan) - inks on paper - 20 x 25 cm - 2020.

\section{First: Descriptive analysis of the artwork (The Devil Departs before Ramadan)}

A- Artwork components: two human elements, a devil, two birds, a snake, a plant, and some arrows are used.

B- The artwork description: in the foreground of the artwork, the artist depicted a bald devil with horns and in a human form, dominated by red color in the body and thick black dots surrounded by red circles, and the face and horns in green color to mix areas of green color in the rest of the body with red. On the left side of the artwork, appears a plant of black and green resembling a cactus and on the opposite side are smaller plants, on top of these plants is a red snake. The background of the devil is occupied by a group of elements. On the right side, a woman appears wearing a cloak that covers her head, from which only her face is visible, and in front of her is a bird. On the left side, a man 
appears in a side position smaller than the devil, in front of him is a crescent, and another bird is on top of him.

C- Elements relationship to the artwork subject: the artist's analogy of the coronavirus in the form of a devil with dots on the body, which appear to be a pandemic. There is a plant on the left side of the artwork, which resembles a cactus, symbolizing patience. The artist's depiction of symbols is related to the topic, which is the end of Corona before Ramadan, such as the crescent, the woman with the head covered, and the two birds that spread peace and tranquility.

\section{Second: Formal analysis of the artwork (The Devil departs before Ramadan)}

\section{A- Artwork elements:}

1- Lines: In his artistic style, the artist defined the artwork elements in black line, followed by a white line, which enriched the artwork elements. He used curved and arc lines in interconnected linear formations.

2- Form: the diversity of the use of elements between human elements, birds, plants and others enriched the design of the artwork.

3- Texture: The variety of textures is a result of the different color techniques. There are elements with color spaces that are free of influences, a rough color texture, and decorative textures in the background of the artwork.

4- Dark and light: the artwork is based on the principle of dark and light, as the artwork elements are characterized by simplification of expression.

5- Color: the colors are compatible. In addition to the artist's use of black and white, he used cold colors represented by green and hot colors represented by red.

6- Space: the spaces of the artwork were occupied by decorative textures due to the color techniques, and some scattered arrows that distinguished the artwork of the artist.

7- Movement: the use of overlapping curved lines resulted in a dynamic character and enhanced the interaction of the recipient with the artwork elements.

\section{B- The structural system in the artwork:}

1- Artwork axes: they depended on the curves which added dynamism and coherence to the artwork.

2- Focus point: it was manifested in the form of the devil in the front of the artwork confirmed by its large size. 
3- Compatibility and Contrast: The contrast in the artwork elements, between good and evil is quite clear. The background of the artwork elements suggests peace, with the exception of the devil element that occupied the front of the artwork.

4- Deletion, addition and modification: The artist followed the method of exaggeration, amplification and elongation. Exaggeration and amplification of the size of the devil's body, as it appeared in his hands, and the principle of elongation became evident in the hands of the woman.

5- Overlays and overlaps: there is partial overlay in the artwork elements, thus emphasizing the unity, interdependence and cohesion of the composition.

6- Depth and flatness: the rich artwork is characterized by flatness and simplification of the artwork elements.

7- Transparency: the principle of transparency is not used in the artwork elements, as the artist used the color spaces with some color effects.

\section{C- Aesthetic foundations in the artwork:}

1- Unity: it was achieved through the harmony of colors, the unity of the elements, and their connection to the idea and content of the artwork.

2- Rhythm: a free rhythm resulting from the repetition and diversity of sizes of human elements, and the diversity of spatial spaces, which gave rise to a lack of a sense of monotony.

3- Balance: there is an axial balance as a result of the middle devil followed by the two birds, which suggests symmetry, but it is not identical due to the different sizes of the elements on both sides of the artwork.

4- Dominance: the dominance of scale is represented in the size of the devil who occupied the front to the artwork, and which the artist portrayed in a broken shape.

5- Proportionality: There is proportionality between the sizes and diversity of the human elements, and also between the masses of the elements and the spatial spaces formed in the background of the artwork.

Through the formal analysis of the artwork, it becomes clear that there are significant relationships between colors, sizes, lines and textures in the artwork. 


\section{D- Formal relations in the artwork:}

1- The relationship between the lines in the artwork: there is a correlation in the lines of the artwork that helped to unite the composition, and the unified thickness of the lines used in the elements confirmed their appearance.

2- The relationship between the sizes in the artwork: the size in the two birds was similar, but the size of the plant element differed significantly on both sides of the artwork, while the sizes of the human elements varied, the size of the devil occupied more space in the front of the artwork, followed by the woman on the top right side of the painting, then the size of the man appears on the left side of the artwork.

3- The relationship between the colors in the artwork: There is a chromatic harmony between hot colors and cold colors with neutral colors.

4- The relationship between the textures in the artwork: The textures varied between soft, coarse and decorative.

\section{Third: Meaning analysis of the artwork (the devil departs before Ramadan)}

A- Internal meanings: The artwork reflects the meanings of peace, as there are elements that suggest peace, where in front of man is the crescent, the woman with covered head, and the two doves are symbols of peace, while the devil appears defeated by the eyes looking down and bowing head and hands folded to the chest in a position of surrender.

B- External meanings: The artist was influenced by popular symbols such as the crescent and the snake. He expressed his inner feeling and beliefs as he portrayed the devil as a symbol of Coronavirus, which he hopes to depart, because devils do not exist in Ramadan.

Through an analysis of selections for the works of the artist Esmat Dawestashy during the Corona period, elements, symbols and color groups appeared to represent the features that distinguished these works of this artist in this period, in addition to the artistic features that the artist has always distinguished in his artworks.

\subsection{The artistic features of Esmat Dawestashy's artworks (during COVID-19 Pandemic)}

Esmat Dawestashy is an artist who has a huge amount of artwork that expresses that period. He used to make an everyday painting about Coronavirus. He says, "It is the case paintings. We are living in an unprecedented event that humanity has not experienced before because of this pandemic. We are detained by choice in our homes to preserve our lives and our health, and so do millions in the world. The artist, painter, writer or filmmaker lives in this state, 
he is already there, so expressing it is possible, and it will be honest, so I make a painting every day, and I invite all artists to do so" (1).

The researcher explains the artistic features of the artworks during Corona as follows: (Predictive artworks during Coronavirus pandemic, Elements and motifs used by the artist to express the Coronavirus pandemic, fine lines in the artwork, color features in the artwork, and artistic features that lasted in during COVID-19 Pandemic).

\section{A- Predictive artworks during Coronavirus pandemic}

The artwork of the artist, Esmat Dawestashy, during the Coronavirus pandemic demonstrates how disasters change the world, and how art may anticipate danger. The experiment (A Painting Every Day) was launched at the beginning of the year 2020 AD. The artist began to depict expressive elements about the Coronavirus pandemic, to express what he feels, where he began to make a painting everyday. The first group of art contains eight paintings entitled (The Devil Is Coming), which portrays the pandemic that has fiercely spread in the entire world from mid-February. He portrayed this group as a mysterious entity that resembles the devil with horns threatening humanity referring the Coronavirus pandemic that the artist expressed before events intensified ${ }^{(2)}$. The artworks varied according to the feelings and emotions that the artist was going through, so he painted (sad angels await), and (the black pandemic hits the beauties), and there are artworks in which he felt optimistic that this pandemic will pass away and it was (Goodbye), and (the devil departs before Ramadan).

\section{B- Elements and motifs used by the artist to express the Coronavirus pandemic}

The artist, Esmat Dawestashy, used elements through which he expressed Coronavirus pandemic, as he used human, angel, devil, birds, fish, snake, crescent, arrows and spiral lines.

One of the elements that the artist used most, which symbolizes coronavirus, was the element of the devil with horns, as in the artworks (The Devil Is Coming), and (The Devil Departs before Ramadan). Besides the devil, he used the snake element, in addition to depicting Corona with signs in black thick dots surrounded by red circles. The artist also used decorative elements, which the researcher sees as carrying symbols and meanings, including spiral lines that suggest corona, and the arrows that suggest sending signals and speech as in the painting (Goodbye), and in (Intimate relations in the time of Corona).

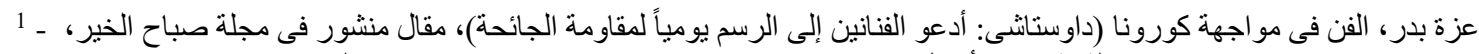

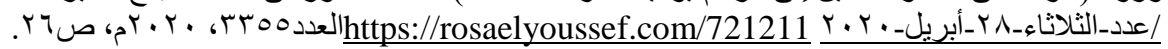

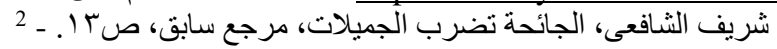


The artist reflected a spiritual sense by depicting the angel wearing clothes resembling a cleric, which was manifested in (Sad Angels Await), although this artwork suggests fear and sadness, and there is an element of the crescent as in (The Devil Departs before Ramadan).

And through the artist's depiction of human elements, he added to them in some of his artworks the withering of eyes and weakness, which was embodied in "The Black Pandemic Hits the Beauties," where the artist explained the repercussions of the crisis on the faces and bodies of women, according to the artist's vision in portraiture based on psychological introspection, and adopted the Egyptian character throughout history, in terms of features, characteristics and $\operatorname{origin}^{(1)}$.

\section{C- Fine lines in the artwork}

By analyzing a selection of artworks by the artist, Esmat Dawestashy, which expressed the Coronavirus pandemic, it is clear that the artist used straight and oblique lines, but the most used lines in his artworks are the spiral, arc and curved lines, which may be overlapping to give his paintings tightness of composition, coherence and unity of the elements. This indicates freedom of expression and fluency of lines. This is in addition to defining the artwork elements in black and then in white, which emphasized and enriched those elements. Through these lines, he added dotted, linear, and arc textures.

\section{D- Color features in the artworks}

Despite the artist's use of strong, explicit colors, they were characterized by economy in color. The most colors used by the artist are red, green, white, and black. Through the group of these colors, there was a contrast between dark colors and light colors, because the main color in the artwork is white. As a result of the use of strong colors, the artist dispensed with transparency in colors. One of the selected paintings is characterized by shadow and light (dark and light) as in the painting (Intimate Relationships in the Time of Corona). There is a diversity of color techniques. In addition to coloring the artistic elements with a single color space, the artist also followed the method of color staining. There is a method of scattering colors by brushing over the basic color of the plastic elements to give these elements the sense of roughness.

\section{E- Artistic features that lasted in Corona time}

There are artistic features specific to the artist Esmat Dawestashy that continued in his artwork during the Corona period. With his spontaneity in expressing his intuition, he followed

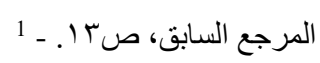


the abstract and symbolic method. Therefore, the plastic elements, especially human elements in the artworks, followed the method of exaggeration, simplification, modification, summarization, flattening, and moving away from the principle of perspective.

In addition to paying attention to the decorations and writings in the Arabic language in the artwork, it is clear that artist has been affected by culture and popular legacies. Through the analysis of artworks, the characters appear to have a cultural dimension that bear Coptic or African roots or are inspired by ancient civilizations, as in works of art (Intimate Relationships in the Time of Corona), (The Black Pandemic Hits the Beauties), and (Goodbye).

By analyzing the works of the artist, Esmat Dawestashy, during the Corona period and studying the plastic elements used in those artworks, the artist also achieved dramatic dimensions for the recipient between anticipation, sadness, isolation, fatigue, optimism, and peace. These dimensions are the internal meanings of the selected artworks.

\section{Results of the research:}

The results of the research are based on the research hypothesis, which is that the work of the artist, Esmat Dawestashy, was affected by the Coronavirus pandemic in the field of painting. By analyzing the artist's works during the Corona period in Egypt, the researcher concluded to a set of results that can be clarified as follows:

1. The study and analysis proved that the artist used plastic elements symbolizing the Coronavirus pandemic. The most prominent element was the devil with horns, and dotted circles. In addition to these elements, the artist used human elements, especially the woman, and used the element of the angel and the bird.

2. The decorations that the artist used, such as spiral lines, symbolize the coronavirus.

3. The plastic elements that the artist used in his expression of the coronavirus pandemic may include elements that were used before corona, but he was creative in how to formulate these elements to express the coronavirus pandemic.

4. The artist continues to be affected by cultural and popular legacies in his artwork, even during the coronavirus pandemic.

5. The artist used red and black colors extensively to express the coronavirus pandemic.

6. It is possible to deduce the upcoming events through the works of the artist, Esmat Dawestashy. 
7. The study proved that by analyzing a group of Esmat Dawestashy's artworks, the artist's optimism for an end of this crisis became clear.

\section{Conclusion}

Through the study and analysis based on the method adopted in this research, it was proven that the works of the artist, Esmat Dawestashy, were affected by the Coronavirus pandemic. It is certain that the artist, Esmat Dawestashy, continued to preserve his artistic characteristics that he acquired throughout his artistic history, but he expressed them during the pandemic period, influenced by the artistic culture, style and symbols in a new formulation. Expressing the Coronavirus pandemic is not limited to wearing a mask, gloves and others. In fact, the artist is a part of society and is affected by the events around him which in turn affect his art. The best example of this is the work of the artist, Esmat Dawestashy, during Corona time. 


\section{Reference}

ا ـ أمجد عبدالسلام عيد (·r.r.r)، زخارف ورموز الفنان عصمت داوستانثى الفاتنة، مقال منشور فى مجلة الثقافة

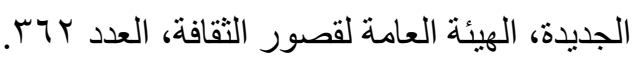

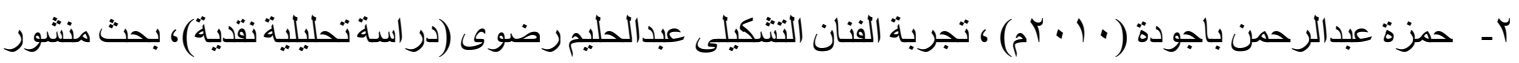
فى مجلة علوم وفنون، مصر، المجلد بr ب، العدد ا.

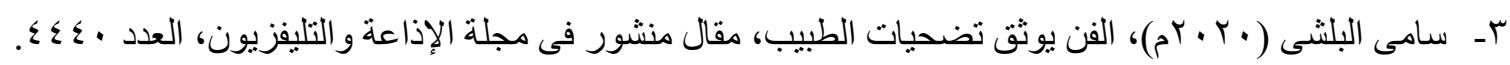

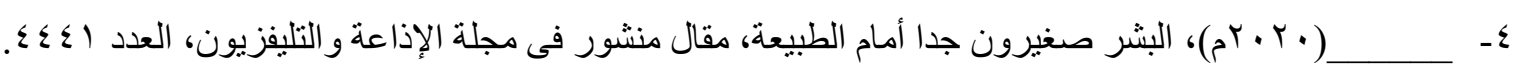

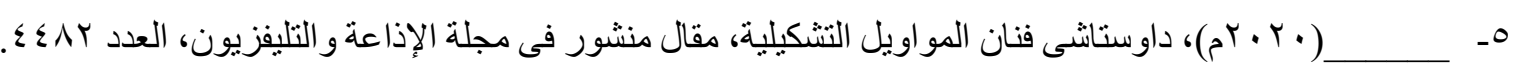

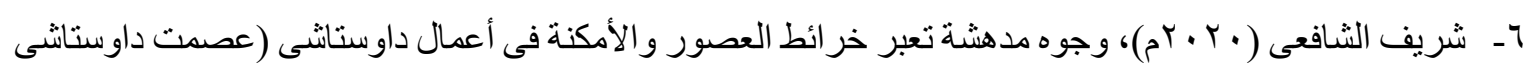

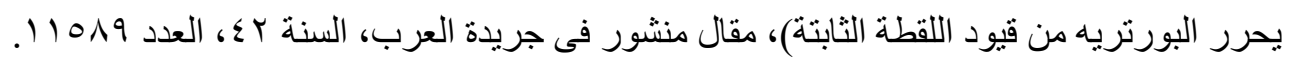

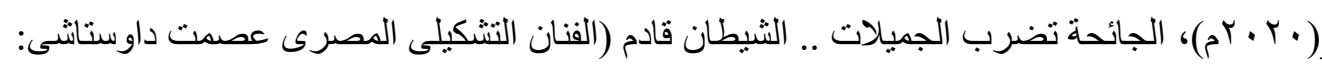
$-V$

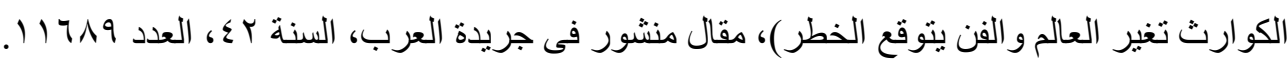

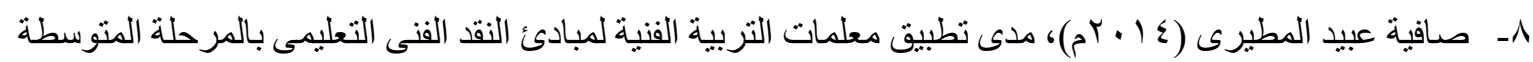

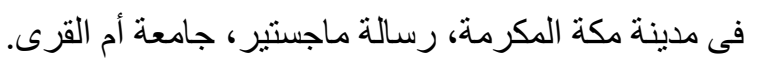

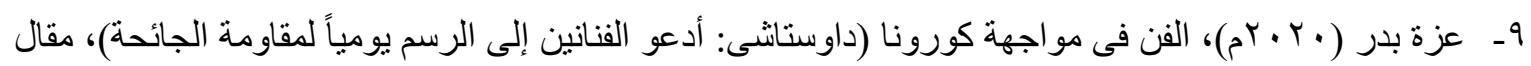

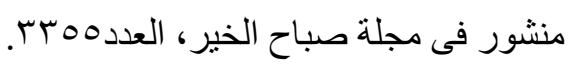

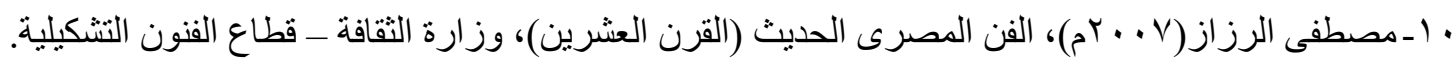
11- Risatti, H., Art Criticism in Discipline - Based Art Education, Source: The Journal of Aesthetic Education, University of Illinois press, Vol. 21, No. 2.

12- https://www.facebook.com

13- https://rosaelyoussef.com

14- https://i.alarab.co. 